\title{
RECREATION: ECONOMIC DEVELOPMENT IMPACT AND SEASONALITY: COMMENT
}

Robert H. Elrod*

Dr. Garbacz has some interesting points in his article, and his future research in this area should prove to be very beneficial. A few suggestions are in order concerning this article and future research. This discussion centers around two concerns. First, the nature of the data used and second, the statistical methods employed are discussed.

The author begins by suggesting that data is needed on the intensity of visits. A major data source which was not used in this paper which gives information on the intensity of visits is the Arkansas State Comprehensive Outdoor Recreational Plan which was conducted in 1968. This study gives the distribution of average annual activity participation by various categories. The study is concerned with many helpful criteria. For example, the demand for supply of outdoor recreational facilities a re given. This type of information certainly can be helpful in Professor Garbacz future research.

One of the major problems that I see is the use of non-manufacturing employment to represent recreation oriented employment. The classification non-manufacturing includes somany diverse types of employment that is far too broad to represent just recreation employment. However, given the nature of published data at the county level, it may be the best one can do.

Professor Garbacz points out that value added in manufacturing in the two county area has not increased. He then concludes that recreation is important to the area because of the paucity of anything else. There is no reason to assume that a two-county area should have a large manufacturing economic base. In fact, there is only one manufacturing industry in Van Buren country. Non-manufacturing employment in the two-county area certainly is affected by the economy of the state and indeed the region. All this points out the need for primary data rather than secondary.

One point in particular needs to be verified. The statement concerning equilibrium of migration and income resulting from the demand for recreation is questionable. Perhaps migratory equilibrium may result, but income equilibrium probably not.

In Table 2, Indicators of Economic Development, the use of end years could be misleading. A suggestion is to work out a rate of growth for the area and the state.

With respect to the seasonality portion of the paper, no one would question the seasonality of employment in recreation based industries. Explaining seasonality with non-manufacturing employment offers nothing substantial. Since non-manufacturing does represent seasonality, what dowe do about it? It is not known whether theseworkers are part-time or not. If they are, then the problem is different. How do you spread tourism over the year?

In the regression analysis, the independent variable is a low intensity recreation activity by the author's definition. Perhaps motel occupancy would be a better regressand. The reason for using camping and fishing was because of the tendency of the visitor to stay overnight and consequently spend more money. Motel and hotel occupancy would certainly be a better measure of visitation in this sense.

*Associate Professor of Quantitative Methods, Georgia State University 
The statistical methods employed raise a few interesting questions. In using a completely random design to determine seasonality, it is not immediately clear that the observations for a month a re randomly distributed over time. However, this procedure is used in other disciplines and is not theoretically disagreeable. As pointed outearlier, to prove that non-manufacturing employment is seasonal begs the question. A more beneficial use of the data would be to develop seasonalindeces by month or by quarter. This is a simple and acceptable procedure. Once these indeces are in hand, then one can begin to approach the problem of seasonality.

In Dr. Garbacz's conclusion, the suggestion is made that a powerful predictive model is in the offing. Is this model going to predict non-manufacturing employment? If so, how is the independent variable, visitation rates, going to be predicted?

The article is entitled "Recreation: Economic Development Impact and Seasonality." If the objective of the article is to point out that recreation, economic development and seasonality are interrelated, the objective is fulfilled. Future research should determine if seasonality of non-manufacturing employment is a problem. If it is, then methods of predicting when it will occur will aid in alleviating the problem.

On the initial problem -- that of poverty of the two county areas: other studies, one here today, have cast a large shadow on the desirability of recreation as an income generator. 